\section{Transición epitelial mesenquimal en carcinomas de células escamosas de cavidad oral relacionado al comportamiento}

\author{
Epithelial-mesenchymal \\ transition in oral squamous cell \\ carcinoma related to behavior
}

Jesús Alfredo Lavalle-Carrasco 1,a, Rogelio González-González 1,b

1 Universidad Juárez del Estado de Durango, Departamento de Investigación, Facultad de Odontología. Durango, Dgo., México. a Cirujano Dentista.

${ }^{\text {b }}$ Doctor en Ciencias Biológicas y de la Salud.

\section{Correspondencia:}

Rogelio González-González

Correo electrónico: rogegg@hotmail.com

Predio Canoas s/n, Los Ángeles, 34000, Durango, Dgo., México.

Coautor:

Jesús Alfredo Lavalle-Carrasco

lavallec@outlook.com

Fecha de recepción: 17/12/18

Fecha de aceptación: 07/01/19
En la actualidad, a nivel mundial, el carcinoma oral de células escamosas (COCE) es el tumor maligno de aparición más común de la región, el cual representa la sexta entidad principal de cáncer por incidencia, con la aparición de más de 300000 casos anuales y alrededor de 150000 muertes ${ }^{1}$. El COCE se caracteriza por su agresividad, alta recurrencia y metástasis linfática y hematógena, además de resistencia al tratamiento y un bajo índice de supervivencia a los 5 años ${ }^{2}$. Un factor que ejerce amplia influencia en la progresión de las células tumorales y el mal pronóstico es el fenómeno de transición epitelial mesenquimal (TEM), el cual se define como la adquisición de características estromales de una célula epitelial, perdiendo su capacidad adhesiva, lo que le permite adoptar un comportamiento agresivo e invasivo.

Cabe recordar que las células cancerosas deben presentar cambios importantes que le permitan su supervivencia, entre ellas se pueden incluir: autosuficiencia de crecimiento, inmortalidad, evasión de la respuesta inmune, adaptación y alteración del metabolismo celular, además de capacidad de invasión y metástasis ${ }^{3}$. Es en este último en donde participa el fenómeno de la TEM, en el cual diferentes marcadores epiteliales que participan en los eventos de adhesión celular e interacción epitelio mesénquima y soporte estromal presentan alteraciones en su función que dotan a la célula de características mesenquimales que le confieren sus capacidades ya descritas. Dichas características pueden ser observadas por marcadores como: vimentina, fibronectina, $\alpha$-SMA (alfa-actina músculo liso), entre otras, además de alteraciones en vías de señalización, principalmente en NF$\mathrm{k} \beta$ (factor de transcripción nuclear kappa beta) y Wnt/ $\beta$-catenina (beta catenina), los cuales en conjunto participan en los procesos de adhesión celular, integridad epitelial, migración, invasión, elevada resistencia a la apoptosis, fibrogénesis, adquisición de fenotipos mesenquimales y producción aumentada de los componentes de la matriz extracelular ${ }^{4-9}$.

Diversos estudios han relacionado el fenotipo mesenquimal de los COCE con la pérdida de la expresión de marcadores de adhesión celular y la ganancia de los marcadores de expresión mesenquimal en un término conocido como "cadherin-switching" tica propia de la TEM, la cual se asocia con resistencia al tratamiento, recurrencia tumoral y mal pronóstico. Además, se ha hipotetizado que el grado presente de TEM en un tumor puede reflejar el crecimiento de este y manifestarse a través de la expresión de proteínas específicas que están relacionadas con la desestabilización de los complejos cadherina/catenina, lo que resulta en una baja regulación de la expresión de E-cadherina (cadheri- 
na epitelial), sobreexpresión citoplasmática de $\beta$-catenina y ganancia de $\mathrm{N}$-cadherina (cadherina neural), la cual se expresa predominantemente en tejidos mesenquimales y neurales ${ }^{9}$. Es importante indicar que la reducción de E-cadherina en la membrana celular, el incremento citoplasmático de $\beta$-catenina y la ganancia de $\mathrm{N}$-cadherina en el componente mesenquimal, pueden ser patrones de expresión relacionados a los procesos de TEM en los COCE, los cuales se involucran con oncogénesis y metástasis ${ }^{6}$. Por lo cual, es importante que en el estudio histopatológico de estos tumores se evalúe la expresión de proteínas asociadas a la TEM para la determinación de posibles fenotipos mesenquimales que conllevaría a tumores de alto riesgo.

\section{Referencias bibliográficas}

1. Ghuwalewala S, Ghatak D, Das P, Dey S, Sarkar S, Alamc N, et al. CD44 (high) CD24 (low) molecular signature determines the Cancer Stem Cell and EMT phenotype in Oral Squamous Cell Carcinoma. Stem Cell Res. 2016;16(2):405-17. doi: 10.1016/j. scr.2016.02.028.

2. Abdalla Z, Walsh T, Thakker N, Ward C. Loss of epithelial markers is an early event in oral dysplasia and is observed within the safety margin of dysplastic and $\mathrm{T} 1$ OSCC biopsies. PLoS One. 2017;12(12):e0187449. doi: 10.1371/journal.pone.0187449.

3. Kumar V, Abbas AK, Aster JC. Neoplasias. En: Kumar V, Abbas AK, Aster JC. Patología estructural y funcional. 9a ed. Barcelona, España: Elsevier; 2015. p. 265-340.
4. Bommi PV, Ravindran S, Raychaudhuri P, Bagchi S. DDB2 regulates Epithelial-to-Mesenchymal Transition (EMT) in Oral/Head and Neck Squamous Cell Carcinoma. Oncotarget. 2018;9(78):34708-34718. doi: 10.18632/oncotarget.26168.

5. Wolf GT, Winter W, Bellile E, Nguyen A, Donnelly CR, McHugh JB, et al. Histologic pattern of invasion and epithelial-mesenchymal phenotype predict prognosis in squamous carcinoma of the head and neck. Oral Oncol. 2018;87:29-35. doi: 10.1016/j.oraloncology.2018.10.010.

6. Zhu GJ, Song PP, Zhou H, Shen XH, Wang JG, Ma $\mathrm{XF}$, et al. Role of epithelial-mesenchymal transition markers E-cadherin, $\mathrm{N}$-cadherin, $\beta$-catenin and ZEB2 in laryngeal squamous cell carcinoma. Oncol Lett. 2018;15(3):3472-3481. doi: 10.3892/ol.2018.7751.

7. Scanlon CS, Van Tubergen EA, Inglehart RC, D'Silva NJ. Biomarkers of Epithelial-Mesenchymal Transition in Squamous Cell Carcinoma. J Dent Res. 2013;92(2):11421. doi: $10.1177 / 0022034512467352$.

8. Benedetti I, Reyes N. Transición epitelial-mesenquimal en la progresión del adenocarcinoma prostático. Iatreia. 2015;28(4):420-33. doi: 10.17533/udea.iatreia. v28n4a07.

9. Angadi PV, Patil PV, Angadi V, Mane D, Shekar S, Hallikerimath $S$, et al. Immunoexpression of Epithelial Mesenchymal Transition Proteins E-Cadherin, $\beta$-Catenin, and N-Cadherin in Oral Squamous Cell Carcinoma. Int J Surg Pathol. 2016;24(8):696-703. doi: $10.1177 / 1066896916654763$. 